\title{
Ozone decomposition kinetics on alumina: effects of ozone partial pressure, relative humidity and repeated oxidation cycles
}

\author{
R. C. Sullivan ${ }^{1 *}$, T. Thornberry ${ }^{1, * *}$, and J. P. D. Abbatt ${ }^{1}$ \\ ${ }^{1}$ Department of Chemistry, University of Toronto, 80 St. George St., Toronto, ON, Canada \\ * present address: Department of Chemistry and Biochemistry, University of California, San Diego, La Jolla, CA, USA \\ *** present address: Aeronomy Lab, NOAA, Boulder, CO, USA
}

Received: 4 March 2004 - Published in Atmos. Chem. Phys. Discuss.: 6 April 2004

Revised: 28 July 2004 - Accepted: 11 August 2004 - Published: 23 August 2004

\begin{abstract}
The room temperature kinetics of gas-phase ozone loss via heterogeneous interactions with thin alumina films has been studied in real-time using $254 \mathrm{~nm}$ absorption spectroscopy to monitor ozone concentrations. The films were prepared from dispersions of fine alumina powder in methanol and their surface areas were determined by an in situ procedure using adsorption of krypton at $77 \mathrm{~K}$. The alumina was found to lose reactivity with increasing ozone exposure. However, some of the lost reactivity could be recovered over timescales of days in an environment free of water, ozone and carbon dioxide. From multiple exposures of ozone to the same film, it was found that the number of active sites is large, greater than $1.4 \times 10^{14}$ active sites per $\mathrm{cm}^{2}$ of surface area or comparable to the total number of surface sites. The films maintain some reactivity at this point, which is consistent with there being some degree of active site regeneration during the experiment and with ozone loss being catalytic to some degree. The initial uptake coefficients on fresh films were found to be inversely dependent on the ozone concentration, varying from roughly $10^{-6}$ for ozone concentrations of $10^{14}$ molecules $/ \mathrm{cm}^{3}$ to $10^{-5}$ at $10^{13}$ molecules $/ \mathrm{cm}^{3}$. The initial uptake coefficients were not dependent on the relative humidity, up to $75 \%$, within the precision of the experiment. The reaction mechanism is discussed, as well as the implications these results have for assessing the effect of mineral dust on atmospheric oxidant levels.
\end{abstract}

\section{Introduction}

Mineral dust is ejected into the troposphere via uplifting from "hot spots" by strong surface winds that travel behind cold frontal systems (Carmichael et al., 1996). Between 1600 and $2000 \mathrm{Tg}$ of mineral dust is predicted to be uplifted into the

Correspondence to: R. C. Sullivan

(rcsulliv@chem.ucsd.edu) atmosphere annually (Ginoux et al., 2001). This estimate is likely to grow with the predicted expansion of arid regions (Sheehy, 1992). Dust storms have become a distinct feature of many regions around the globe, including Asia, South America, East and West Africa (Shultz, 1979; Prospero et al., 1979). These mineral dust aerosols can have long atmospheric lifetimes and be transported over large distances. Particles smaller than $10 \mu \mathrm{m}$ have atmospheric lifetimes of several days (Prospero, 1999) and can be transported thousands of kilometers across the North Atlantic and North Pacific Oceans (Duce et al., 1980).

Mineral aerosols provide a potential surface for the adsorption of gases leading to processing of the aerosol surface. These aerosols can also provide surfaces for heterogeneous chemistry (Dentener et al., 1996). One such heterogeneous reaction of interest is the decomposition of ozone on mineral aerosols. This is of particular interest due to ozone's importance as a greenhouse gas, atmospheric oxidant and tropospheric toxic pollutant. The destruction of ozone by mineral dust aloft has been suggested by various field studies. Prospero et al. (1995) suggested that the large surface area available on dust might explain their observations of anticorrelated $\mathrm{O}_{3}$ concentrations with aerosol concentrations as the $\mathrm{O}_{3}$ was destroyed during transit with the dust plume. Dentener et al. (1996) modeled the impact of reactive mineral dust surfaces on the troposphere and predicted up to $10 \%$ loss of ozone nearby a dust source area due to interactions of $\mathrm{N}_{2} \mathrm{O}_{5}, \mathrm{HO}_{2}$ and $\mathrm{O}_{3}$ with mineral aerosols. They cite the lack of a realistic laboratory uptake coefficient measurement of $\mathrm{O}_{3}$ on dust particles as the most uncertain parameter in their study. Further evidence for $\mathrm{O}_{3}$ loss on mineral aerosols is given by de Reus et al. (2000) who observed reduced $\mathrm{O}_{3}$ mixing ratios over the North Atlantic Ocean associated with a dust layer originating from northern Africa. The $\mathrm{O}_{3}$ loss was interpreted to be from direct reactive uptake of $\mathrm{O}_{3}$ on the mineral aerosol surface (50\%) and indirect $\mathrm{O}_{3}$ loss from heterogeneous removal of $\mathrm{HNO}_{3}(50 \%)$. 
Mineral dust aerosols are heterogeneous mixtures of primarily mineral oxides. Michel et al. (2002) report chemical compositions of China loess as primarily $48 \% \mathrm{Si}, 22 \%$ $\mathrm{Ca}, \% 10 \mathrm{Fe}, 10 \% \mathrm{Al}$ and Saharan dust as $80 \% \mathrm{Si}, 1 \%$ $\mathrm{Ca}, 7 \% \mathrm{Fe}$ and $8 \% \mathrm{Al}$ (C and $\mathrm{O}$ excluded). Other researchers have investigated the reactive uptake of ozone on both authentic mineral dust samples, and on the individual components of mineral aerosols such as $\mathrm{CaO}, \mathrm{Al}_{2} \mathrm{O}_{3}$, $\mathrm{Fe}_{2} \mathrm{O}_{3}$ and $\mathrm{SiO}_{2}$. In particular, Suzuki et al. (1979) showed that the reactivity of ozone on metal oxides decreased with ozone exposure, and Alebić-Juretić et al. (1992) used a fluidized bed-reactor to show that the relative effectiveness of ozone destruction was alumina $>$ wood ash $>$ silicagel $>$ Saharan sand $>$ calcite $>\mathrm{NaCl}$. They also found that the kinetics of ozone loss could be described by two different half-lives produced by a fast initial loss of ozone followed by a much slower loss (Alebić-Juretić et al., 2000). Similar results have been reported for Saharan Dust (Hanisch and Crowley, 2003) where it was also found that at high $\mathrm{O}_{3}$ concentrations the $\mathrm{O}_{3}$ uptake ceased after an exposure period due to surface passivation. Michel et al. (2002) and Michel et al. (2003) measured the uptake of $\mathrm{O}_{3}$ on $\alpha-\mathrm{Al}_{2} \mathrm{O}_{3}$, $\alpha-\mathrm{Fe}_{2} \mathrm{O}_{3}, \mathrm{SiO}_{2}$, China loess and Saharan sand, and claim that some component of the loss is catalytic, i.e. the total number of ozone molecules lost is greater than the number of active sites on the mineral surfaces. They report that the $\mathrm{O}_{3}$ reactive uptake exhibited the following trend: $\alpha-\mathrm{Fe}_{2} \mathrm{O}_{3}>\alpha$ $\mathrm{Al}_{2} \mathrm{O}_{3}>\mathrm{SiO}_{2}$. For a more comprehensive review of mineral dust kinetics, the reader can consult Usher et al. (2003a).

Given that alumina is both a principal mineral in dust aerosol and one of the more reactive components for ozone destruction, we chose to begin our mineral dust studies with alumina before moving on to authentic dust samples. In this work, we paid particular attention to parameters of the chemistry that had not been addressed in previous experiments. In particular, for the first time we have measured the BET surface areas of the equivalent alumina films in situ. Also, we have investigated for the first time the effect of the simultaneous presence of water vapour on the kinetics by performing the experiments at elevated relative humidity. This latter experiment is motivated by previous studies that show that considerable amounts of water adsorb to alumina surfaces under atmospheric relative humidity conditions (Al-Abadleh and Grassian, 2003). We have used a static-mode, UV absorption apparatus for these studies because it can operate under high relative humidities whereas Knudsen cells, which have been used for recent studies of ozone/ mineral dust kinetics (Michel et al., 2002; Michel et al., 2003; Hanisch and Crowley, 2003), cannot.

\section{Experimental}

\subsection{Film preparation}

Mineral oxide films were prepared by mixing $0.3 \mathrm{~g}$ of alphaaluminium oxide $\left(\alpha-\mathrm{Al}_{2} \mathrm{O}_{3}\right.$, Alfa Aesar, $99.9 \%$ pure) with $10 \mathrm{ml}$ of methanol to create a slurry. About $2 \mathrm{ml}$ of the slurry was dripped into pyrex tubes of dimensions 20 -cm-long by 1.4-cm-i.d. The tube was rolled to evenly spread the slurry across the tube while being dried by a gentle stream of dry air. The resulting film covered the entire inner area of the tube and, to the eye, was fairly uniform in thickness. The coated tubes were then stored for at least $24 \mathrm{~h}$ in a purge box with a constant flow of air that has been dried, filtered and purged of carbon dioxide.

\subsection{Surface area determination}

As described in Sect. 3.1, the specific surface area of the films was determined by measuring the change in pressure from the adsorption of a known volume of krypton gas when the $\mathrm{Kr}$ was exposed to the film at $77 \mathrm{~K}$. In particular, the alumina-coated pyrex tube was placed in a 22-cm-long, 3$\mathrm{cm}$-i.d. stainless steel chamber with copper-gasket seals that could be entirely immersed in liquid nitrogen in a large dewar. This approach was developed in our lab for measuring the surface areas of soot films in situ (Aubin and Abbatt, 2003).

\subsection{Kinetics experiments}

The ozone decomposition experiments were conducted in a static chamber at room temperature with online ozone detection by UV absorption at $254 \mathrm{~nm}$. Figure 1 displays the instrumental setup. The dimensions of the tube used as the absorption cell were 54-cm-long and 3.1-cm i.d. and the cell was equipped with quartz windows at each end. The $254 \mathrm{~nm}$ radiation from a mercury pen-ray lamp first passed through an interference filter, then through a lens, the absorption cell, another lens and onto a silicon photodiode. A second beam of light exited the opposite side of the penray lamp, and through a second, equivalent interference filter onto a reference photodiode. The ratio of the main and reference photodiode signals was used to reduce the noise in the lamp's signal due to short timescale fluctuations. The background signal ratio was measured both at the beginning and at the end of each ozone exposure, after all the ozone had been destroyed and the signal had stabilized. With this set-up, a typical ozone detection limit was on the order of $2 \times 10^{12}$ molecules $/ \mathrm{cm}^{3}$ (signal-to-noise ratio of one, over a 1 -second integration period).

Ozone was generated by passing a stream of oxygen through a commercial ultraviolet ozone generator. The oxygen/ozone mixture passed through a silica gel trap immersed in an ethanol bath cooled to $\sim 193 \mathrm{~K}$ with liquid nitrogen. After about one hour of collection, the $\mathrm{O}_{3} / \mathrm{O}_{2}$ mixture was 


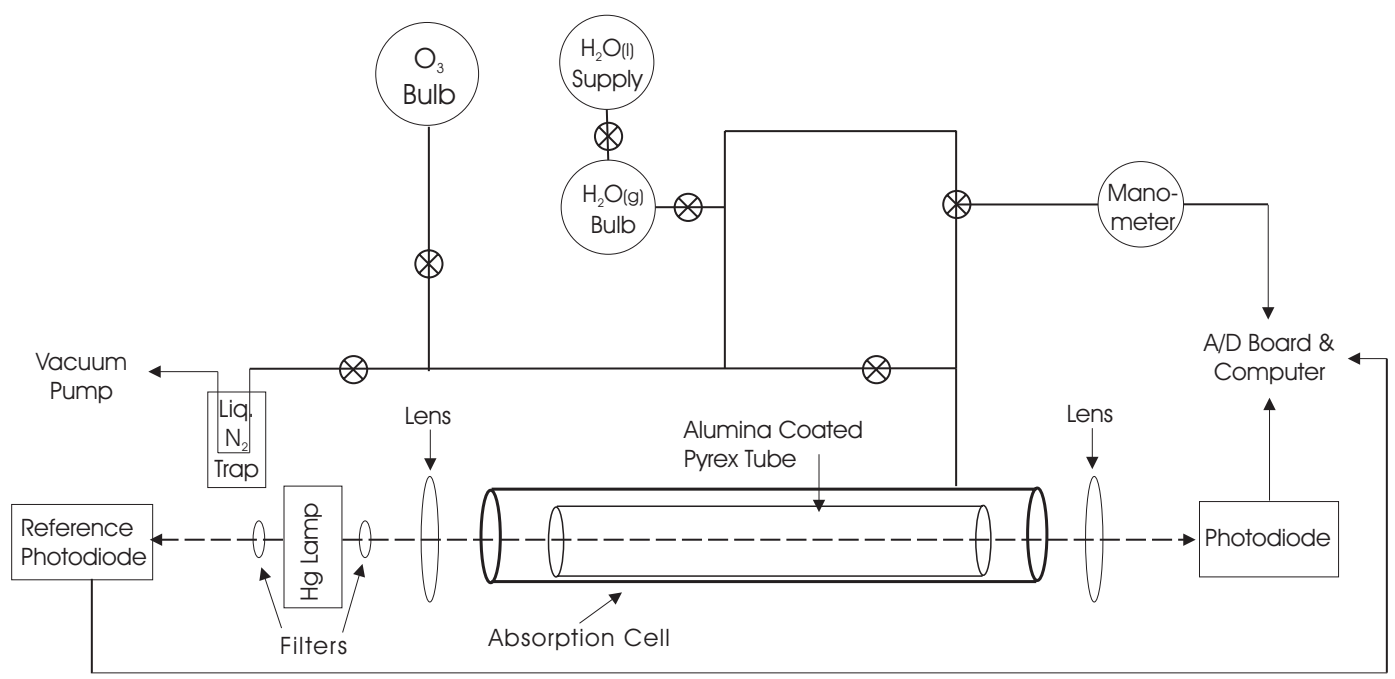

Fig. 1. Experimental apparatus.

pulled off the silica gel into an evacuated glass bulb. The absorption chamber was passivated with ozone prior to the beginning of a day's experiments by flooding the chamber with a large amount of ozone from the ozone bulb and letting it sit in the chamber for at least 30 minutes before it was evacuated. The alumina film was then removed from the purge box and immediately placed in the reaction chamber that had been evacuated for 20 minutes down to a few thousandths of a millibar by a rotary vacuum pump and then opened to atmosphere. A liquid nitrogen trap was placed in front of the line from the vacuum pump to prevent any pump oil from back streaming into the reaction chamber.

To expose the film to ozone a teflon line connecting the ozone bulb, absorption cell and manometer was filled with a measured pressure of $\mathrm{O}_{3} / \mathrm{O}_{2}$, the dominant component being oxygen. A three-way valve was then used to simultaneously switch the 100 Torr manometer to measure the absorption cell's pressure and add a pulse of ozone to the cell from the small volume of teflon tubing connecting the manometer to the three-way valve. The pressure in the absorption cell was typically between 0.1 and 0.7 mbar. The signal intensity from the photodiodes was recorded at $2 \mathrm{~Hz}$ using a commercial data acquisition board and Labview on a desktop computer.

To investigate the effect of relative humidity, a large evacuated bulb was filled to a measured pressure with water vapour from a smaller bulb containing deionised, degassed water. The large bulb was then closed and the teflon line filled with $\mathrm{O}_{3} / \mathrm{O}_{2}$ as usual. Instead of using the three-way valve, the valve between the filled teflon line and the large water vapour bulb was opened to allow the gases to mix, and then the valve to the reaction chamber was opened for 2 seconds and closed again. This introduced both water vapour and ozone to the reaction chamber simultaneously. Other experiments were performed by first putting the ozone into the large bulb, followed by the water vapour.
Lastly, we note that we did some experiments where benzene was added in place of ozone, to test for the rapidity by which expansion from the teflon line into the evacuated absorption cell occurs. Benzene was chosen for these studies because it suffers no irreversible loss on glass surfaces and it also absorbs to some degree at $254 \mathrm{~nm}$. We observed that the increase of absorption to a steady state value occurred over the timescale of a second or less, after the valve to the absorption cell was opened. That is, expansion to the absorption cell is essentially instantaneous relative to the timescale at which ozone was observed to decay in our kinetics studies.

\section{Results and discussion}

\subsection{Film surface area determination}

As described above, the number of moles of adsorbed Krypton was measured on alumina films as a function of $\mathrm{Kr}$ pressure at $77 \mathrm{~K}$, as shown for a typical film in Fig. 2. There is a linear dependence between the adsorbed amount and the $\mathrm{Kr}$ partial pressure for small surface coverages that saturates at higher pressures. For the highest partial pressures, multilayer formation and much larger uptakes prevail. The film surface area $(S A)$ is determined from the saturation level, which we attribute to monolayer formation. Specifically:

$S A=$ Moles of adsorbed $\mathrm{Kr}$ at saturation $* 6.02 \times 10^{23} * S A_{\mathrm{Kr}}$

where $S A_{K r}$ is the cross-section of a $\mathrm{Kr}$ atom, generally taken to be $0.205 \mathrm{~nm}^{2}$ (Rouquerol, 1999).

As shown in Fig. 3, the surface areas of the films were linearly dependent on the total mass of the alumina. Because the geometric surface area of each film was roughly the same, i.e. the alumina covered the entire inner surface of the glass tube insert, we can infer from Fig. 3 that the Krypton can diffuse through the entire film and access each alumina particle. If there were significant burial of some of the alumina, 


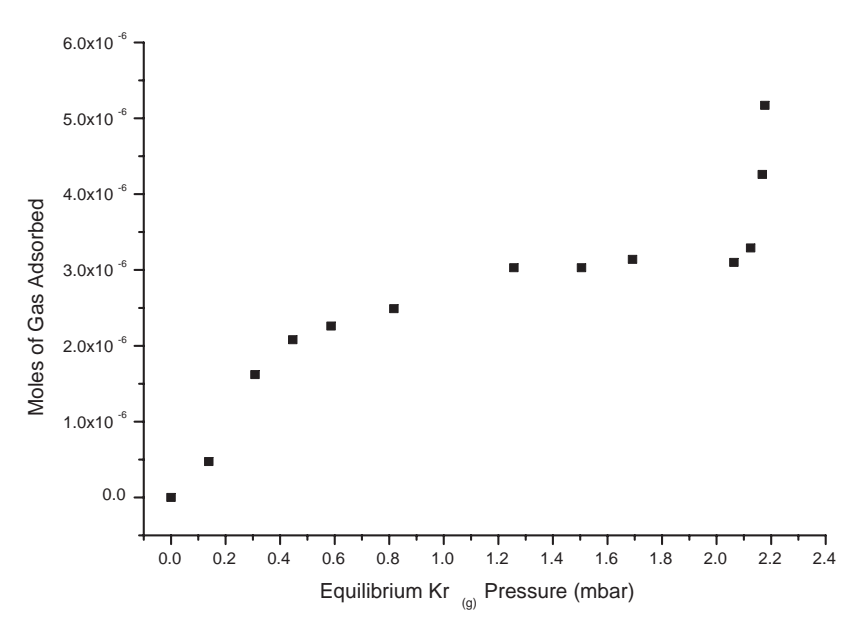

Fig. 2. Adsorption isotherm of $\operatorname{Kr}(\mathrm{g})$ on alumina film at $77 \mathrm{~K}$. Total surface area of the film is $3700 \mathrm{~cm}^{2}$ and the mass is $138 \mathrm{mg}$.

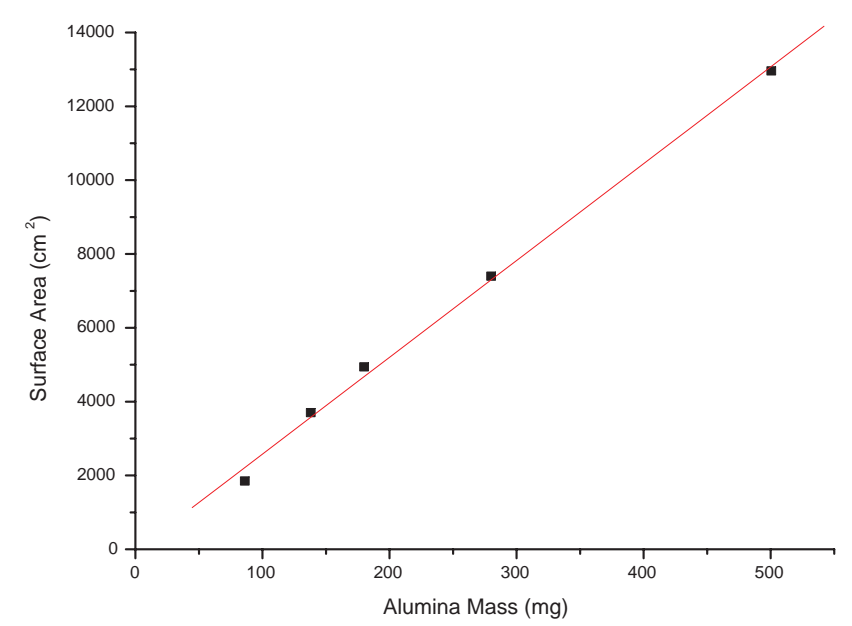

Fig. 3. Dependence of film surface area on film mass. The slope of the plot is $22 \mathrm{~cm}^{2} / \mathrm{mg}$.

as happens in very thick samples, then the measured surface area would show some degree of saturation at high samples masses (Keyser et al., 1991; Underwood et al., 2000). For very thick samples, the surface area would be independent of sample mass. As shown in Fig. 3, the linearity of this plot holds up to total masses of close to $500 \mathrm{mg}$ and down to $100 \mathrm{mg}$. Surface areas could not be directly measured for films with masses considerably smaller than $100 \mathrm{mg}$ because of experimental uncertainties that arise in measuring the uptake of a small amount of Krypton.

It is important to point out that all of the kinetics studies described below were conducted on sample masses lower than $100 \mathrm{mg}$. This mass of alumina is at the upper limit of what can be reasonably used for the ozone kinetics experiments; larger film masses have ozone decay rates that are too fast to quantify. However, the surface area of films with masses less than $100 \mathrm{mg}$ could not be accurately determined.
Thus the same alumina films used to characterise the specific surface area could not be used for the kinetics experiments. To determine the total surface areas of the films used for the kinetics experiments, we assumed that the linear relationship demonstrated in Fig. 3 holds for these thinner films. The alumina films used for the surface area and kinetics experiments were prepared in exactly the same manner, only the mass, and thus surface area, differed.

In kinetics studies on mineral dust conducted by Michel et al. (2002) and by Hanisch and Crowley (2003), it was found that for a fixed geometric surface area, linearity between measured uptake coefficients and total sample mass held for geometric-surface-area to mass ratios of as small as $100 \mathrm{~cm}^{2} / \mathrm{g}$. It can be inferred that in this regime, the total surface areas also scale with sample mass. We note that the ratios of geometric-surface-area to mass ratios used in our work $\left(>500 \mathrm{~cm}^{2} / \mathrm{g}\right)$ are considerably larger than these values, providing independent confirmation that our samples are sufficiently thin to allow gases to diffuse throughout the film depth.

\subsection{Ozone loss kinetics: deactivation with ozone exposure}

A typical decay of ozone after admission to an evacuated reaction cell containing an alumina-coated tube insert is shown as the curve marked as the "1st Oxidation" in Figs. 4a and $b$. As can be seen the decay is well approximated by a first-order decay both over long (Fig. 4a) and short timescales (Fig. 4b). After a few hundred seconds, the ozone concentration has decayed to undetectable values, i.e. $<2 \times 10^{12}$ molecules $/ \mathrm{cm}^{3}$, at which point the reaction cell was evacuated and sequential additions of the same, i.e. to within $10 \%$, concentration of ozone were made to the cell. As can be seen in Fig. 4b, the decay rate of ozone decreased with each addition until, at short times only, the rate was similar to that observed in the reaction cell in the absence of an alumina film. The decay of ozone in the absence of alumina is likely due to both reaction on the pyrex surface but also with the few metal and o-ring elastomer surfaces present in the absorption cell. The control experiment shown in Fig. 4 is for the first exposure of a bare pyrex tube. In other experiments, not shown, we observed that this control decay rate became smaller with repeated exposures.

It is important to note that at long times the films were still considerably more reactive to ozone (Fig. $4 \mathrm{a}$ ) than the control. Indeed, this is also true at short times, when compared to controls that had also been repeatedly exposed.

It is clear from these observations that the alumina can be deactivated by exposure to ozone, presumably by consumption of active sites on the surface. Thomas et al. (1997) determined that the active sites for the adsorption and decomposition of ozone on alumina at $77 \mathrm{~K}$ are aluminum ions $\left(\mathrm{Al}^{3+}\right)$. By integrating the number of ozone molecules required to deactivate the surface to the point where the short-term loss is approaching that in the absence of alumina, we arrive at a 

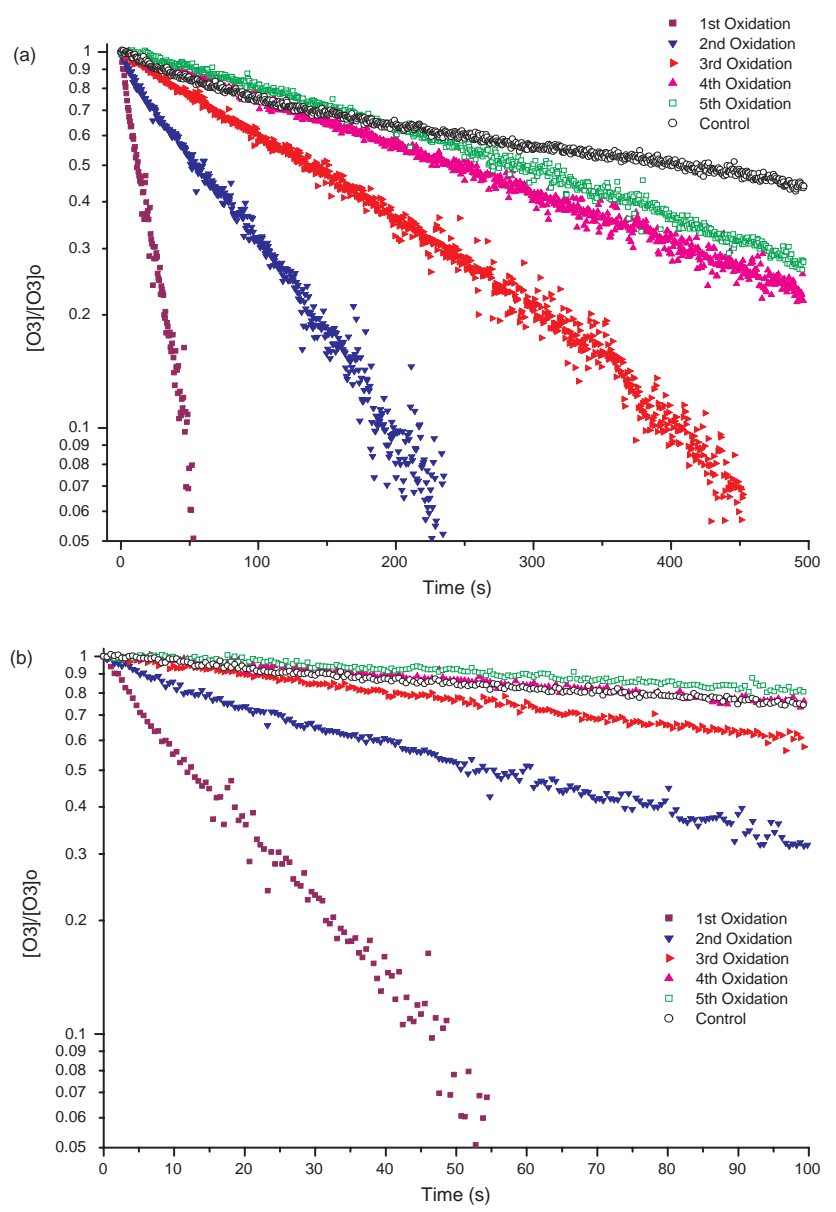

Fig. 4. Decays of $\mathrm{O}_{3}$ on an alumina film, with subsequent additions of $\mathrm{O}_{3}$ to the film $\left(\left[\mathrm{O}_{3}\right]=4.1-4.8 \times 10^{13}\right.$ molecules $\left.\mathrm{cm}^{-3}\right)$. Control (o) is the ozone decay on an empty pyrex tube in the passivated reaction chamber. (a) long-term decay of ozone demonstrating reactivity of the alumina films even when passivated by successive oxidations with $\mathrm{O}_{3}$. (b) short-term decay shows rate of ozone destruction on alumina film is similar to that of the background wall loss after three additions of ozone.

active surface site coverage of $(1.4 \pm 0.4) \times 10^{14}$ sites $/ \mathrm{cm}^{2}$, the average value of 3 studies. For entities that are on the order of $0.15 \mathrm{~nm}$ in radius, such as an aluminum atom, a full surface coverage is roughly $1 \times 10^{15} / \mathrm{cm}^{2}$. For alumina, the number of aluminum atoms at the surface will be significantly lower than this, given the stoichiometry of the alpha aluminum oxide species $\left(\mathrm{Al}_{2} \mathrm{O}_{3}\right)$. Thus, our measurement of the number of active sites implies that a large fraction of the aluminum atoms at the surface of the alumina are available for reaction. Indeed, this is a lower estimate to the total number of active sites because the film still exhibits considerable reactivity, even after a number of repeated exposures.

The deactivation of similar mineral surfaces has been previously reported by a number of workers. The other measurements of the number of active sites include those of Michel

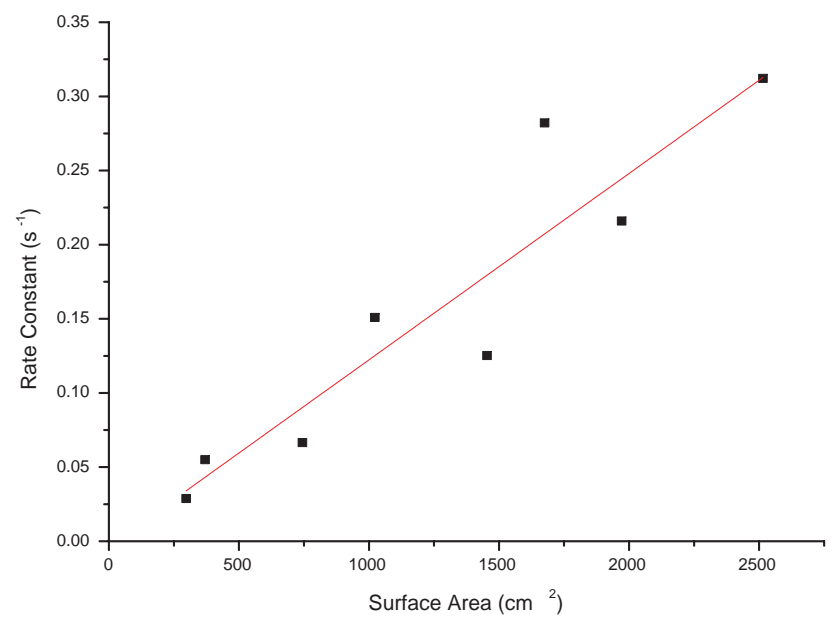

Fig. 5. Dependence of first-order rate constants for ozone loss on fresh alumina surfaces as a function of film surface area $\left(\left[\mathrm{O}_{3}\right]=1.4\right.$ $3.0 \times 10^{13}$ molecules $\mathrm{cm}^{-3}$ ).

et al. (2002) who report a value of $10^{15} / \mathrm{cm}^{2}$ or greater for alumina and by Hanisch and Crowley (2003), who measured $2 \times 10^{14} / \mathrm{cm}^{2}$ on Saharan dust. Our value of greater than $1.4 \times 10^{14} / \mathrm{cm}^{2}$, i.e. that which corresponds to loss of significant reactivity at short times, is thus consistent with these published values. The fact that the films remain significantly reactive to ozone, even after repeated ozone doses, is consistent with the conclusion of Michel et al. (2002) that the films exhibit some degree of catalytic activity towards ozone destruction.

\subsection{Ozone loss kinetics: dependence on the initial ozone} concentration

Our kinetics results are given in Figs. 5 and 6. In Fig. 5, the first-order-loss rate constant is plotted versus the alumina film surface area, for a relatively uniform partial pressure of ozone. To within the precision of the data, the observed kinetics scale linearly with the surface area, an experimental verification that we are operating in the linear mass dependent regime where all the surface area is accessible to the reacting ozone molecules.

In Fig. 6, the initial uptake coefficient is plotted as a function of the initial ozone concentration in the reaction cell. The uptake coefficients $(\gamma)$ were calculated from the following expression:

$\gamma=\left(4 * k^{I} * V\right) /(c * S A)$

where $c$ is the mean velocity of the ozone gas-phase molecule, $k^{I}$ is the observed initial first-order rate constant for ozone loss (from the first $10 \mathrm{~s}$ of data), $S A$ is the total surface area of the alumina film, and $V$ is the volume of the reactor. Given that reversible ozone adsorption has not been observed in chemistry of this type in previous studies, we believe this uptake coefficient is due solely to reaction and thus 


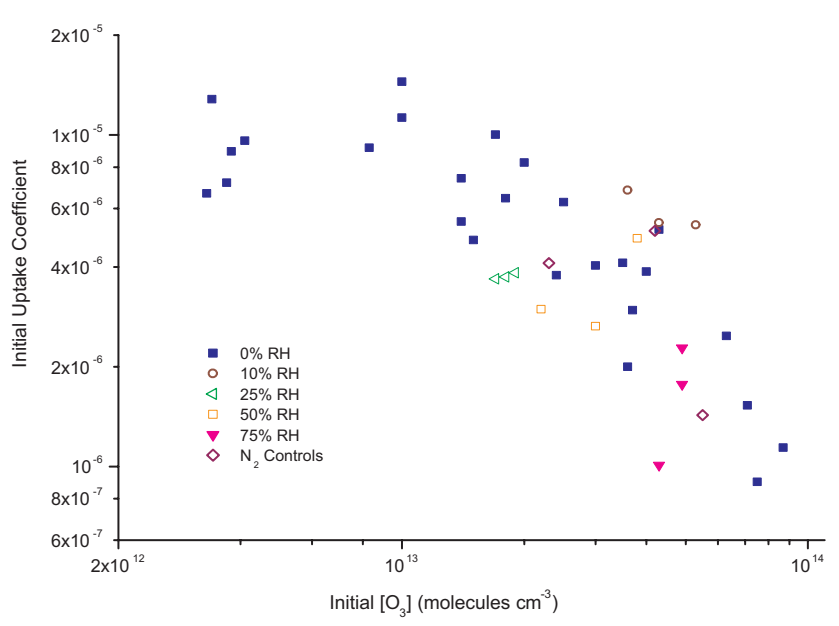

Fig. 6. Dependence of initial ozone uptake coefficients $(\gamma)$ as a function of ozone concentration and relative humidity. All experiments were conducted on fresh alumina films which had never been previously oxidised. The $\mathrm{N}_{2}$ controls involved simultaneously filling the reaction chamber with $\mathrm{O}_{3}$ and 2.8, 9.9, and 22.5 mbar of $\mathrm{N}_{2}$ instead of $\mathrm{H}_{2} \mathrm{O}_{(\mathrm{g})}$. The uncertainty of the initial uptake coefficients $(\gamma)$ is estimated to be $25 \%$ and that of the initial $\left[\mathrm{O}_{3}\right]$ to be $20 \%$.

can be viewed as a gas-surface reaction probability. Note that in this paper we are reporting what are frequently referred to as the BET uptake coefficients, i.e. we are assuming that the ozone molecules sample the full surface area before reacting.

Relationship (E2) assumes that there is no gas-phase diffusion limitation to the kinetics, an assumption that is well justified for the relatively small uptake coefficients and low total pressures ( 0.1 to 0.7 mbar) employed in most of this study. As a test of this, we conducted a number of experiments where ozone was simultaneously added with nitrogen gas such that the total pressure in the reactor was between 2.8 and 22.5 mbar (see Fig. 6). The initial uptake coefficients measured at these elevated total pressures did not deviate significantly from those measured in experiments where there was no additional carrier gas added to the reactor (aside from the $\mathrm{O}_{2}$ that was mixed with the ozone), and the gas-phase diffusion constraint was considerably lower.

Although there is some scatter in the data in Fig. 6, it is nevertheless clear that there is an inverse relationship between the uptake coefficient and the ozone concentration for most of the data. A similar dependence has been observed over the range of ozone concentrations of roughly $6 \times 10^{10}$ to $10^{13}$ molecules $/ \mathrm{cm}^{3}$ by Hanisch and Crowley (2003) in their work on Saharan dust. For ozone concentrations between $10^{11}$ and $10^{12}$ molecules $/ \mathrm{cm}^{3}$, no dependence was reported by Michel et al. (2002) in their work on alumina. We attribute some of the scatter in the data in Fig. 6 to a combination of uncertainties in the total film surface area and the value of the initial ozone concentration. The error in the rate constant determination is estimated to be $5-10 \%$, and the error in the surface area determination to be $20 \%$ (from uncertainties in weighing the film mass and from the extrapolation of Fig. 3). This leads to an estimated overall error in $\gamma$ of $\sim 25 \%$. The uncertainty in the initial $\left[\mathrm{O}_{3}\right]$ is estimated to be $20 \%$. However, we also cannot rule out that there is a variable nature in the reactivity of the alumina films from sample to sample. In particular, we noticed that if the fresh films were not stored before use in a clean, dry environment their reactivity was somewhat suppressed relative to those that were. Although we only studied the initial kinetics on films that had been stored at least $24 \mathrm{~h}$ in this clean environment, it is possible that some variability could still arise from this effect.

The reason for the inverse dependence between the reaction probability and the ozone concentration is not immediately clear. If it were true that the amount of ozone that reacts in the time period over which the initial uptake coefficient is determined, i.e. the first $10 \mathrm{~s}$ or so, were comparable to the number of active sites available, then the inverse dependence could be simply due to the consumption of active sites. However, this appears to not be the full explanation, particularly for the runs at lower concentrations of ozone. For the data in Fig. 4, in the first $10 \mathrm{~s}$ of the initial exposure, only $0.8 \times 10^{16}$ sites are consumed by a starting ozone concentration of $4.6 \times 10^{13}$ molecules $/ \mathrm{cm}^{3}$. (This quantity is calculated by multiplying the total number of ozone molecules in the cell by the fraction of ozone lost in the first 10 s (i.e. roughly 0.5 ) and by assuming that the loss of one ozone molecule is equivalent to consumption of one surface site.) The total number of surface sites on this film, though, is at least $5 \times 10^{16}$, as measured from the deactivation experiments. If all the active sites are equally reactive, then this small fraction of active sites consumed (i.e. $\left.\left(0.8 \times 10^{16}\right) /\left(5 \times 10^{16}\right)\right)$ should not have a significant effect on the uptake kinetics.

Other possibilities include a suggestion (Hanisch and Crowley, 2003) that ozone has the ability to bind to the surface in both unreactive and reactive configurations, and that the non-reactively bound ozone can block the binding to the reactive sites. In this model, higher concentrations of ozone will lead to an increased blocking of reactive sites and an overall decrease in the reaction rates. This explanation is most likely to be valid for the higher ozone concentration runs. Alternatively, it is possible that there is some range of reactivity exhibited by the array of surface sites. The initial uptake coefficients are larger than those measured at a later time because fewer sites have been consumed via reaction and the most reactive sites react first. Finally, we note that a Langmuir-Hinshelwood mechanism, where ozone reversibly binds to the surface, can exhibit an inverse dependence of uptake coefficients on ozone concentration (Poschl et al., 2001). The reason for the inverse dependence with increasing ozone concentration is that the rate of the surface reaction, i.e. ozone finding an active site with which to react, is capped in the limit of surface saturation but the rate of collisions of the gas-phase ozone molecules with the surface is not. 
In comparing our results to others in the literature, we note that Michel et al. (2002) did not observe the inverse dependence of the uptake coefficients on ozone concentrations for alumina whereas Hanisch and Crowley (2003) do report the inverse dependence, albeit on Saharan dust samples. One possible explanation for the differing alumina results is that we operated at somewhat higher ozone concentrations than did Michel et al. (2002), i.e. we deactivated our films more rapidly. In support of this, we note that at the lowest ozone concentrations used in our study $\left(\leq 10^{13}\right.$ molecules $\left./ \mathrm{cm}^{3}\right)$, the uptake coefficients are somewhat insensitive to the concentration of ozone. However, if no dependence of the uptake coefficient on ozone exists for low concentrations, we note that our uptake coefficients in this regime are somewhat lower than those of Michel et al. (2002) who report an initial uptake coefficient of $(8 \pm 5) \times 10^{-5}$ on $\alpha-\mathrm{Al}_{2} \mathrm{O}_{3}$. The reasons for the discrepancy are not clear although we note that we measured our BET surface areas in situ whereas Michel et al. (and other researchers) do not.

\subsection{Ozone loss kinetics: regeneration}

For alumina-coated tubes that had been deactivated in the manner just described, it was found that a significant degree of reactivation could be achieved by placing the tubes in a closed container that was purged with dry, $\mathrm{CO}_{2}$-free air for periods of a few days. As a specific example, a film which had an initial uptake coefficient of $6 \times 10^{-6}$ was passivated by repeated exposures to ozone until the short-time decay reached values typical of control values without alumina present. For a similar concentration of ozone, the decay was measured again after the film remained in a purged environment for $54 \mathrm{~h}$. The initial decay was significantly larger than a comparable decay in a control experiment with no alumina present, and it corresponded to an uptake coefficient of $9 \times 10^{-7}$. Three other experiments also exhibited significant regeneration, although to a highly variable degree with recoveries of reactivity ranging from a few percent to over $50 \%$ of the initial uptake coefficient. We note that this observation of partial recovery of initial reactivity has also been observed in the Saharan dust studies of Hanisch and Crowley (2003).

\subsection{Ozone loss kinetics: dependence on relative humidity}

It is well known that water can adsorb to mineral oxide surfaces in significant, i.e. monolayer, amounts for atmospherically appropriate relative humidities. Goodman et al. (2003) found that complete monolayer formation occurred on $\alpha$ $\mathrm{Al}_{2} \mathrm{O}_{3}$ at $17 \% \mathrm{RH}$ for $296 \mathrm{~K}$. Al-Abadleh and Grassian (2003) have used infrared absorption spectroscopy to demonstrate that water adsorbs to alumina in amounts equivalent to roughly 4 monolayers at close to $75 \% \mathrm{RH}$ at room temperature. The structure of a hydrated alumina surface is reported to be an intermediate between $\alpha-\mathrm{Al}_{2} \mathrm{O}_{3}$ and $\gamma-\mathrm{Al}(\mathrm{OH})_{3}$ with a surface terminated by a monolayer of $\mathrm{OH}$ under ambient conditions (Eng et al., 2000). Our alumina powder was stored in its original container before being coated on the pyrex tubes. We can assume that the powder had previously adsorbed an appreciable amount of water and is more accurately described as being a mixture of $\alpha-\mathrm{Al}_{2} \mathrm{O}_{3}$ and $\gamma$ $\mathrm{Al}(\mathrm{OH})_{3}$. Although our alumina films were exposed to a vacuum of less than a few thousandths of a millibar we did not heat our alumina films prior to the kinetics experiments. Grassian (2002) reports that infrared spectroscopy shows oxide powders still retain some adsorbed water after pumping overnight. Thus it is reasonable to assume that our alumina surfaces were hydrated when prepared and that much of this water was not removed by storage in a purge box or by vacuum prior to the exposure to ozone (Al-Abadleh and Grassian, 2003).

Given that almost all other reactive studies on mineral dust have been performed under dry conditions, we conducted some experiments with increased levels of water vapour in the gas phase. This was achieved by mixing the water vapour and ozone in a glass bulb before addition to the reaction cell. The results from these experiments are included in Fig. 6. Within the scatter of the data, it can be seen that there is no dependence of the kinetics on the relative humidity. Although Hanning-Lee et al. (1996) qualitatively refer to some preliminary results on the role of water, we believe this is the first time a quantitative study of this type has been performed.

The lack of a dependence on relative humidity came somewhat as a surprise given the large amounts of water that are known to adsorb. However, we make a couple of points. First, as discussed above, our alumina surfaces were likely already partially hydrated prior to the simultaneous addition of water vapour and ozone. If the alumina film already contains surface-bound water, the impact of the addition of water vapour could be significantly lessened. Second, this finding is in agreement with other results from our research group that the kinetics of the loss of ozone on an unsaturated fatty acid, i.e. linoleic acid, are also unaffected by a relative humidity of 50\% relative to dry conditions (Thornberry and Abbatt, 2003). Although the mechanisms of these two reactive systems are very different, there are basic similarities in that ozone must find a site on the surface for it to react and it is known that water adsorbs to long chain, unsaturated fatty acids in similar, roughly monolayer amounts (Asad et al., 2004). The reasons for the minimal effects due to the adsorbed water most probably arise from a combination of the reactive chemistry being considerably more exothermic than the relatively weak physisorption interaction that the water experiences with the surface and because the diffusion times through the very thin layer of water existing on these surfaces are extremely short. Clearly, it is also possible that the water simply adsorbs at sites that are physically separate from the sites reactive to ozone. Finally, we also note that the manner by which we conducted the experiment was to add the water and ozone simultaneously. Hence, we may not have given enough time for the water to fully equilibrate with the surface. 


\subsection{Reaction mechanism}

We interpret the observation of decreasing reactivity with increasing ozone exposure as due to consumption of surface active sites via reaction:

$\mathrm{SS}+\mathrm{O}_{3} \longrightarrow \mathrm{SS}-\mathrm{O}+\mathrm{O}_{2}$

The motivation for the reaction proceeding through a simple one-step mechanism is that the ratio of oxygen molecules produced relative to the loss of ozone molecules is close to unity for experiments conducted on unheated Saharan dust samples (Hanisch and Crowley, 2003). Clearly, Saharan dust is a combination of a number of minerals, most prominently alumina, iron oxide and silica, but it is not unreasonable to believe that the reaction mechanism is similar on these oxide surfaces.

However, for a number of reasons, we believe the full mechanism is not as simple as just outlined. First, there is evidence from the work of Hanisch and Crowley (2003) that the yield of $\mathrm{O}_{2}$ can be larger than unity in some cases, in particular if Saharan dust samples are heated to drive off strongly adsorbed water. Second, there is evidence from the inverse dependence of the kinetics on the ozone concentration that suggests that ozone may also unreactively bind to alumina. Finally, in detailed surface spectroscopy studies of the decay of ozone on manganese oxide surfaces, there is evidence for the formation of a peroxy species on the surface that is thought to arise from the following mechanism ( $\mathrm{Li}$ and Oyama, 1998; Li et al., 1998):

$\mathrm{SS}+\mathrm{O}_{3} \longrightarrow \mathrm{SS}-\mathrm{O}+\mathrm{O}_{2}$

$\mathrm{SS}-\mathrm{O}+\mathrm{O}_{3} \longrightarrow \mathrm{SS}-\mathrm{O}_{2}+\mathrm{O}_{2}$

$\mathrm{SS}-\mathrm{O}_{2} \longrightarrow \mathrm{SS}+\mathrm{O}_{2}$

This regeneration mechanism need not only proceed through the additional steps (R2) and (R3) but instead could alternatively proceed via the SS-O sites reacting together to yield molecular oxygen:

$\mathrm{SS}-\mathrm{O}+\mathrm{SS}-\mathrm{O} \longrightarrow 2 \mathrm{SS}+\mathrm{O}_{2}$

With the data obtained in our experiment, we are not able to determine whether the reaction proceeds through the peroxy mechanism or not. Instead, an experiment that employs some form of surface-specific spectroscopy is needed.

This mechanism (R1, R2 and R3 or R1 and R4) is consistent with the partial regeneration of reactivity that we observe when the oxidized alumina films are placed in the ozone-free chamber. It is also consistent with the observations that some degree of catalytic ozone destruction occurs. In particular, for there to be catalytic activity there must be a certain degree of active site regeneration during the timescale of the experiment. At this point, we are not able to assess what affects the rate of reactivity regeneration. Li and Oyama (1998) report that the energy of desorption of $\mathrm{O}_{2}(\mathrm{R} 3)$ increases with decreasing surface coverage. Thus as more $\mathrm{O}_{2}$ desorbs from the mineral oxide surface, it will become increasingly more difficult for successive $\mathrm{O}_{2}$ molecules to desorb and regenerate the surface reactivity. This could explain why we only see partial regeneration of our alumina surfaces after a few days of isolation in the purged environment.

\section{Conclusions and atmospheric implications}

Our findings are in full support of previous investigations of the chemical interaction between ozone and alumina surfaces. There is an efficient loss process for ozone on alumina surfaces that can occur with gas-surface reaction probabilities similar to those required to make this chemistry a significant loss process for ozone in dust clouds (Usher et al., 2003a). In particular, in the study of Dentener et al. (1996), it was concluded that reaction probabilities of roughly $10^{-5}$ were needed for this heterogeneous process to represent an important ozone sink. We note that for atmospheric ozone mixing ratios of tens of $\mathrm{ppb}$, the initial uptake coefficients we infer from our studies (Fig. 6) are at least this large.

To estimate the effect of ozone decomposition on alumina surfaces we used field measurements of a dust event over the North Atlantic Ocean reported by de Reus et al. (2000). At an altitude of $4 \mathrm{~km}$ the total aerosol surface area was $1.58 \mathrm{~cm}^{2} \mathrm{~m}^{-3}$, the mean $\left[\mathrm{O}_{3}\right]$ was $31 \mathrm{ppb}$, temperature and pressure were $279 \mathrm{~K}$ and $620 \mathrm{hPa}$, respectively. This $\left[\mathrm{O}_{3}\right]$ corresponds to $\sim 5.0 \times 10^{11}$ molecules $\mathrm{cm}^{-3}$, below the $\left[\mathrm{O}_{3}\right]$ we were capable of working with for our experiments. From Fig. 6 we extrapolate a $\gamma \sim 1.5 \times 10^{-5}$ at this ozone concentration. Using Eq. (2) we estimate the e-folding lifetime of ozone to be $\sim 55$ days. This is a rather large lifetime however, several points should be made regarding this estimation. First, actual mineral dust aerosol is a complex mixture of numerous metal oxides and other components, some of which have greater reactivity towards ozone than alumina does (e.g. Michel et al., 2002). Second, as our work and others has shown, the reactivity of alumina depends on the oxide's history as the surface reactivity can be reduced by exposure to ozone but also regenerated over time. The reactivity of the mineral dust will also depend on other chemical aging processes such as being coated by nitrate, sulphate and/or organics (Usher et al., 2003b). Third, the dust event measurements reported by de Rues et al. (2000) were made in the free troposphere 3-5 days after the initial injection of the dust aerosol into the atmosphere. Initial dust surface areas near the source could be much higher than the values used here, ranging from $5-21 \mathrm{~cm}^{2} \mathrm{~m}^{-3}$ for Asian dust storms, for example (Zhang and Carmichael, 1999). This will result in a correspondingly shorter ozone lifetime (18 to 4.2 days for these example surface areas).

We also find that there is a substantial degree of surface deactivation that occurs with increasing ozone exposure. 
However, the reactivity of the oxidized films can be partially regenerated over a time period of days in an environment free of ozone, water vapour and carbon dioxide. This regeneration may be the reason that there still remains some reactivity on the film, even after significant ozone exposure. The strong inverse dependence of the initial uptake coefficients on the ozone concentration may be due to the co-binding of ozone in a non-reactive manner, as well as to the consumption of reactive sites. For the first time, we show that when the experiments are conducted with water vapour added simultaneously with ozone, there is no substantial effect on the kinetics.

From an atmospheric perspective, significant aspects of the findings include the small role that water vapour appears to have on the kinetics, thus validating the atmospheric significance of previous kinetics studies done under dry conditions. In addition, the observation of partial reactivity regeneration on a timescale of a few days is potentially very important and consistent with previous claims that the ozone destruction is catalytic to some degree. In our studies we used ozone concentrations that are somewhat higher than those prevalent in the troposphere. Under these conditions, the surfaces were deactivated on timescales of minutes whereas the timescale for substantial surface regeneration was longer, otherwise we would not have seen substantial deactivation. In the troposphere, ozone concentrations are roughly two orders of magnitude smaller than those used in our deactivation experiments such as that shown in Fig. 4. Deactivation will be comparably slower and so closer to the timescale for partial reactivity regeneration. Determining the balance between these deactivation and reactivation processes is clearly crucial to better determine the degree of catalytic behavior that will prevail under atmospheric conditions and to recommend a reaction probability most appropriate for atmospheric modeling.

Acknowledgements. The authors would like to thank D. Aubin for help with surface area determinations and NSERC for partial financial support.

Edited by: M. Ammann

\section{References}

Al-Abadleh, H. A. and Grassian, V. H.: FT-IR Study of Water Adsorption on Aluminum Oxide Surfaces, Langmuir, 19, 341-347, 2003.

Alebić-Juretić, A., Cvitaš, T., and Klasinc, L.: Ozone destruction on powders, Ber. Bunsenges. Phys. Chem., 96, 493-495, 1992.

Alebić-Juretić, A., Cvitaš, T., and Klasinc, L.: Kinetics of heterogeneous ozone interactions, Chemosphere, 41, 667-670, 2000.

Asad, A., Mmereki, B. T., and Donandson, D. J.: Enhanced uptake of water by oxidatively processed oleic acid, Atmos. Chem. Phys. Discuss., 4, 4019-4038, 2004.
Aubin, D. G. and Abbatt, J. P. D.: Adsorption of gas-phase nitric acid to n-hexane soot: Thermodynamics and mechanism, J. Phys. Chem. A., 107, 11 030-11 037, 2003.

Carmichael, G. R., Zhang, Y., Chen, L.-L., Hong, M.-S., and Ueda, H.: Seasonal variation of aerosol composition at Cheju island, Korea, Atmos. Environ., 30, 2407-2416, 1996.

de Reus, M., Dentener, F., Thomas, A., Borrmann, S., Ström, J., and Lelieveld, J.: Airborne observations of dust aerosol over the North Atlantic Ocean during ACE 2: Indications for heterogeneous ozone destruction, J. Geophys. Res., 105, 15 263-15 275, 2000.

Dentener, F. J., Carmichael, G. R., Zhang, Y., Lelieveld, J., and Crutzen, P. J.: Role of mineral aerosol as a reactive surface in the global troposphere, J. Geophys. Res., 101, 22 869-22 889, 1996.

Duce, R. A., Unni, C. K., Ray, B. J., Prospero, J. M., and Merrill, J. T.: Long-range atmospheric transport of soil dust from Asia to the Tropical North Pacific: Temporal variability, Science, 209, 1522-1524, 1980.

Eng, P. J., Traintor, T. P., Brown Jr., G. E., Waychunas, G. A., Newville, M., Sutton, S. R., and Rivers, M. L.: Structure of the hydrated $\alpha-\mathrm{Al}_{2} \mathrm{O}_{3}$ (0001) surface, Science, 288, 1029-1033, 2000 .

Goodman, A. L., Bernard, E. T., and Grassian, V. H.: Spectroscopic study of nitric acid and water adsorption on oxide particles: Enhanced nitric acid uptake kinetics in the presence of adsorbed water, J. Phys. Chem. A., 105, 6443-6457, 2001.

Grassian, V. H.: Chemical reactions of nitrogen oxides on the surface of oxide, carbonate, soot and mineral dust particles: Implications for the chemical balance of the troposphere, J. Phys. Chem. A., 106, 860-877, 2002.

Ginoux, P., Chin, M., Tegen, I., Prospero, J. M., Holben, B., Dubovik, O., and Lin, S. J.: Sources and distributions of dust aerosols simulated with the GOCART model, J. Geophys. Res., 106, 20 555-20273, 2001.

Hanisch, F. and Crowley, J. N.: Ozone decomposition on Saharan dust: an experimental investigation, Atmos. Chem. Phys., 3, 119-130, 2003.

Hanning-Lee, M. A., Brady, B. B., Martin, L. R., and Syage, J. A.: Ozone decomposition on alumina: Implications for solid rocket motor exhaust, Geophys. Res. Lett., 23, 1961-1964, 1996.

Keyser, L. F., Moore, S. B., and Leu, M. T.: Surface-Reaction and Pore Diffusion in Flow-Tube Reactors, J. Phys. Chem., 95, 54965502, 1991.

Li, W. and Oyama, S. T.: Mechanism of Ozone Decomposition on a Manganese Oxide Catalyst, 2. Steady-State and Transient Kinetic Studies, J. Am. Chem. Soc., 120, 9047-9052, 1998.

Li, W., Gibbs, G. V., and Oyama, S. T.: Mechanism of Ozone Decomposition on a Manganese Oxide Catalyst, 1. In Situ Raman Spectroscopy and Ab Initio Molecular Orbital Calculations, J. Am. Chem. Soc., 120, 9041-9046, 1998.

Michel, A. E., Usher, C. R., and Grassian, V. H.: Heterogeneous and catalytic uptake of ozone on mineral oxides and dusts: a Knudsen cell investigation, Geophys. Res. Lett., 29, 10.1029/2002GL014896, 2002.

Michel, A. E., Usher, C. R., and Grassian, V. H.: Reactive uptake of ozone on mineral oxides and mineral dusts, Atmos. Environ., 37, 3201-3211, 2003.

Poschl, U., Letzel, T., Schauer, C., and Niessner, R.: Interaction of Ozone and Water Vapor with Spark Discharge Soot Aerosol 
Particles Coated with Benzo[a]pyrene: $\mathrm{O}_{3}$ and $\mathrm{H}_{2} \mathrm{O}$ Adsorption, Benzo[a]pyrene Degradation, and Atmospheric Implications, J. Phys. Chem. A., 105, 4029-4041, 2001.

Prospero, J. M.: Long-range transport of mineral dust in the global atmosphere: Impact of African dust on the environment of the southeastern United States, Proc. Natl. Acad. Sci. USA, 96, 3396-3403, 1999.

Prospero, J. M., Schmitt, R., Cuevas, E., Savoie, D. L., Graustein, W. C., Turekian, K. K., Volz-Thomas, A., Diaz, A., Oltmans, S. J., and Levy II, H.: Temporal variability of summer-time ozone and aerosols in the free troposphere over the eastern North Atlantic, Geophys. Res. Lett., 22, 2925-2928, 1995.

Prospero, J. M.: Mineral and sea salt concentrations in various ocean regions, J. Geophys. Res., 84, 725-731, 1979.

Rouquerol, F.: Adsorption by Powders and Porous Solids: Principles, Methodology and Applications, Academic Press, San Diego, 1999.

Schultz, L.: Sahara dust transport over the North Atlantic OceanModel circulations and measurements in Saharan Dust: Mobilisation, Transport, edited by Morales, C., pp. 267-277, John Wiley, New York, 1979.

Sheehy, D. P.: Perspective on desertification on grazingland and ecosystems in north China, Ambio, 21, 303-307, 1992.
Suzuki, S., Hori, Y., and Koga, O.: Decomposition of ozone on natural sand, Bull. Chem. Soc. Japan, 52, 3103-3104, 1979.

Thomas, K., Hoggan, P. E., Mariey, L., Lamotte, J., and Lavalley, J. C.: Experimental and theoretical study of ozone adsorption on alumina, Catalysis Letters, 46, 77-82, 1997.

Thornberry, T. and Abbatt, J. P. D.: Heterogeneous reaction of ozone with liquid unsaturated fatty acids: detailed kinetics and gas-phase product studies, Phys. Chem. Chem. Phys., 6, 84-93, 2004.

Underwood, G. M., Li, P., Usher, C. R., and Grassian, V. H.: Determining accurate kinetic parameters of potentially important heterogeneous atmospheric reactions on solid particle surfaces with a Knudsen cell reactor, J. Phys. Chem. A., 104, 819-829, 2000.

Usher, C. R., Michel, A. E., and Grassian, V. H.: Reactions on mineral dust, Chem. Rev., 103, 4883-4939, 2003a.

Usher, C. R., Michel, A. E., Stec, D., and Grassian, V. H.: Laboratory studies of ozone uptake on processed mineral dust, Atmos. Environ., 37, 5337-5347, 2003b.

Zhang, Y. and Carmichael, G. R.: The Role of Mineral Aerosol in Tropospheric Chemistry in East Asia - A Model Study, Journal of Applied Meteorology, 38, 353-366, 1999. 